\title{
Macrolide-resistant Mycoplasma pneumoniae in adolescents with community-acquired pneumonia
}

\author{
Naoyuki Miyashita ${ }^{1 *}$, Yasuhiro Kawai ${ }^{2}$, Hiroto Akaike ${ }^{2}$, Kazunobu Ouchi ${ }^{2}$, Toshikiyo Hayashi ${ }^{1}$, Takeyuki Kurihara ${ }^{1}$ \\ Niro Okimoto ${ }^{1}$ and the Atypical Pathogen Study Group
}

\begin{abstract}
Background: Although the prevalence of macrolide-resistant Mycoplasma pneumoniae isolates in Japanese pediatric patients has increased rapidly, there have been no reports concerning macrolide-resistant M. pneumoniae infection in adolescents aged 16 to 19 years old. The purpose of this study was to clarify the prevalence and clinical characteristics of macrolide-resistant M. pneumoniae in adolescent patients with community-acquired pneumonia.
\end{abstract}

Methods: A total of 99 cases with M. pneumoniae pneumonia confirmed by polymerase chain reaction (PCR) and culture were analyzed. Forty-five cases were pediatric patients less than 16 years old, 26 cases were 16 to 19-year-old adolescent patients and 28 cases were adult patients. Primers for domain $V$ of $23 S$ rRNA were used and DNA sequences of the PCR products were compared with the sequence of an $M$. pneumoniae reference strain.

Results: Thirty of 45 pediatric patients (66\%), 12 of 26 adolescent patients (46\%) and seven of 28 adult patients (25\%) with M. pneumoniae pneumonia were found to be infected with macrolide-resistant M. pneumoniae (MR patients). Although the prevalence of resistant strains was similar in pediatric patients between 2008 and 2011, an increase in the prevalence of resistant strains was observed in adolescent patients. Among 30 pediatric MR patients, 26 had an A-to-G transition at position 2063 (A2063G) and four had an A-to-G transition at position 2064 (A2064G). In 12 adolescent MR patients, 10 showed an A2063G transition and two showed an A2064G transition, and in seven adult MR patients, six showed an A2063G transition and one showed an A2064G transition.

Conclusions: The prevalence of macrolide-resistant M. pneumoniae is high among adolescent patients as well as pediatric patients less than 16-years old. To prevent outbreaks of $M$. pneumoniae infection, especially macrolide-resistant $M$. pneumoniae, in closed populations including among families, in schools and in university students, physicians should pay close attention to macrolide-resistant M. pneumoniae.

Keywords: Mycoplasma pneumoniae, Macrolide-resistant, Community-acquired pneumonia, 235 rRNA

\section{Background}

Mycoplasma pneumoniae is a common causative pathogen of respiratory infections in children and adults, accounting for as many as $10-30 \%$ of all cases of community-acquired pneumonia (CAP) [1]. M. pneumoniae pneumonia is specified for weekly reporting by specially designated sentinel clinics in accordance with the Japanese Infectious Diseases Control Law. Between 2001 and 2010, the average number of cases of M. pneumoniae pneumonia per sentinel clinic per year was 16.2 [2]. In 2011, especially the second half of the year, an epidemic of M. pneumoniae infection occurred

\footnotetext{
*Correspondence: nao@med.kawasaki-m.ac.jp

'Department of Internal Medicine I, Kawasaki Medical School, 2-1-80

Nakasange, Kita-ku, Okayama 700-8505, Japan

Full list of author information is available at the end of the article
}

throughout Japan and the incidence was the highest observed during the past decade, with the number of cases per sentinel clinic reaching 36.3 per year [2]. Many outbreaks of M. pneumoniae have occurred in closed populations including among families, in high schools, and in university students. During 2010 and 2011, a similar surge in M. pneumoniae infections was described in other countries especially in northern Europe [3-11].

Although M. pneumoniae pneumonia is usually mild in severity, macrolide-resistant $M$. pneumoniae with mutations in the 23S rRNA gene has emerged in pediatrics patients with CAP $[12,13]$. Recently, the prevalence of macrolideresistant $M$. pneumoniae isolates in Japanese pediatric patients has increased sharply [14]. More than $60 \%$ of $M$.

\section{Biomed Central}

(c) 2012 Miyashita et al.; licensee BioMed Central Ltd. This is an Open Access article distributed under the terms of the Creative Commons Attribution License (http://creativecommons.org/licenses/by/2.0), which permits unrestricted use, distribution, and reproduction in any medium, provided the original work is properly cited. 
pneumoniae strains in pediatric patients showed high resistance to 14- and 15-membered ring macrolides with MICs greater than or equal to $32 \mathrm{mg} / \mathrm{L}$ [14]. In contrast to pediatric patients, the prevalence of macrolide-resistant $M$. pneumoniae infection in adult patients is low [15]. Previous reports were limited to pediatric patients less than 16 years old or adults ( $\geq 20$ years old), and there are no reports investigating high school-aged patients (16 to 18-years old) $[12,13,15-18]$. Several studies to determine the influence of age in CAP patients indicated that $M$. pneumoniae pneumonia is significantly more common in younger patients and especially in the 10-20-year-old age group [1]. The purpose of this study was to clarify the prevalence and clinical characteristics of macrolide-resistant $M$. pneumoniae in adolescents, especially high school-aged patients, with CAP.

\section{Methods}

\section{Patients}

This study was conducted as a part of CAP studies that investigated the prevalence and clinical features of atypical pneumonia and evaluated the usefulness of diagnostic methods for the diagnosis of this condition. All patients with CAP who visited 12 institutions participating in the Atypical Pathogen Study Group from January 2008 to December 2011 were enrolled in this study. The diagnosis was based on clinical signs and symptoms of lower respiratory tract infection (cough, fever, productive sputum, dyspnea, chest pain, or abnormal breath sounds) and the presence of new infiltrates on chest radiographs that were at least segmental and were not caused by preexisting or other known causes. Informed consent was obtained from all patients; the study protocol was approved by the Ethics Committee at Kawasaki Medical School.

\section{Microbiological laboratory tests}

Microbiological tests, such as Gram stain, cultures, realtime polymerase chain reaction (PCR), urinary antigen tests and serological tests, were performed as described previously [19]. Nasopharyngeal swab specimens were obtained from all patients and, if pleural fluid and sputum were available, a Gram stain test and a quantitative culture were obtained. Blood cultures were obtained from all adolescent and adult patients. Sputum data were only evaluated when the Gram stain test revealed numerous leukocytes ( $>25$ in a $\times 100$ microscopic field) and few squamous epithelial cells ( $<10$ in a $\times 100$ microscopic field). Invasive methods, such as bronchoscopic examination, were employed to obtain specimens in some patients after full explanation of the procedures. A bronchoscopic examination was undertaken for clinical indications. These specimens were also used for culturing and PCR. Cultures for M. pneumoniae and Legionella species were performed on pleuropneumonialike organism broth (Difco, Detroit, MI, USA) and buffered charcoal-yeast extract alpha agar, respectively. Cultures for
Chlamydophila pneumoniae and C. psittaci were performed using cycloheximide-treated HEp-2 cells grown in a 24-well cell culture plate. All specimens were examined twice. Culture confirmation was done by fluorescent-antibody staining with C. pneumoniae and C. psittaci species-specific and genusspecific monoclonal antibodies. The target DNA sequences for PCR were a region of the $53-\mathrm{kDa}$ gene for C. pneumoniae, the major outer membrane gene for Chlamydia, the P1 cytadhesin gene for $M$. pneumoniae, and the nucleotide sequence of the 5S-ribosomal DNA for Legionella. DNA was extracted from respiratory samples using a QIAamp DNA Mini Kit (QIAGEN K. K., Tokyo, Japan) in accordance with the manufacturer's instructions. The assays were performed as described previously [19]. Nasopharyngeal swab specimens were also tested for influenza A and B viruses by a direct enzyme immunoassay.

Paired serum samples were collected at intervals of at least 4 weeks after onset. Complement fixation (CF) tests were done in all patients for antibodies to influenza A and B viruses, adenovirus, respiratory syncytial virus, cytomegalovirus, and parainfluenza virus types 1, 2, and 3. Antibodies against $M$. pneumoniae were measured with the use of a particle agglutination (PA) test (Serodia-Myco II kit, Fujirebio, Tokyo, Japan), Legionella species by a microagglutination test (detection of L. pneumophila serogroups $1 \sim 6$, L. bozemanii, L. dumoffii, L. gormanii, and L. micdadei), and Coxiella burnetii by an indirect immunofluorescence test. A microimmunofluorescence test was used for the titration of IgG and IgM antibodies against chlamydial species using formalinized elementary bodies of C. pneumoniae KKpn-15, C. trachomatis $\mathrm{L} 2 / 434 / \mathrm{Bu}$, and $C$. psittaci Budgerigar-1 strains as antigens. Rheumatoid factors were absorbed with GullSORB (Meridian Bioscience Inc., $\mathrm{OH}$, USA) before IgM titration. In addition to serology, culturing, and/or PCR, urinary antigen tests (Binax NOW, Binax Inc. Portland, ME, USA) for S. pneumoniae and $L$. pneumophila were performed in adolescent and adult patients.

\section{Criteria for the determination of microbial etiology}

The microbial etiology was classified as "definitive", "presumptive", or "unknown" as reported previously [19]. A definitive etiology was defined if one of the following conditions was present: (1) blood or pleural fluid cultures yielding the presence of bacterial or fungal pathogen; (2) urinary antigen test results positive for L. pneumophila or $S$. pneumoniae; (3) respiratory specimen culture or PCR results positive for $M$. pneumoniae, C. psittaci or Legionella species; (4) nasopharyngeal antigen test results positive for influenza A and B viruses; (5) a fourfold increase in the antibody titer for viruses, $M$. pneumoniae (to $\geq 1: 160$ ), Legionella species (to $\geq 1: 128$ ), C. burnetii, or Chlamydia species (IgM or IgG); or (6) a single increase in IgM titer for Chlamydia species $\geq 1: 32$. A presumptive etiology was 
considered if any of the following conditions were present: (1) an organism showing heavy $\left(\geq 10^{7} \mathrm{cfu} / \mathrm{mL}\right)$ or moderate $\left(10^{6} \mathrm{cfu} / \mathrm{mL}\right)$ growth of a predominant bacterium on a sputum culture in combination with Gram stain findings; (2) any microorganism isolated from bronchoscopic specimens when its concentration reached $\geq 10^{5} \mathrm{cfu} / \mathrm{mL}$ in quantitative culture; (3) an antibody titer of $\geq 1: 320$ for $M$. pneumoniae in either an acute-phase or convalescentphase serum sample; (4) an antibody titer of $\geq 1: 256$ for Legionella species in either an acute-phase or convalescentphase serum sample; or (5) respiratory specimens culture of PCR results positive for C. pneumoniae. An unknown etiology was considered if any of the following conditions were present: (1) respiratory specimens culture results were "normal flora"; (2) an organism showing light growth on a sputum culture; or (3) cases not fulfilling any of the above conditions.

\section{Detection of point mutations associated with resistance in domain $\mathrm{V}$ of $23 \mathrm{~S}$ rRNA}

A search for mutations at sites 2063, 2064, and 2617 in the M. pneumoniae 23S rRNA domain V gene region was performed using a direct sequencing method in samples with a positive PCR result, as reported previously $[12,15,18]$. Specifically, nested PCR was performed using a thermal cycler (PCR Thermal Cycler Dice Gradient, Takara Bio, Inc., Shiga, Japan) with primers (Sigma-Aldrich, Japan), Taq polymerase (Takara Ex Taq Version; Takara Bio, Inc.), and extracted DNA. The PCR products were purified using a QIAquick PCR Purification Kit (QIAGEN). The purified products were electrophoresed in a 3\% Nusieve 3:1 agarose gel (Lonza) and, after the single band was confirmed, labeled using a BigDye Terminator V3.1 cycle sequencing kit (Applied Biosystems) and applied to an ABI Prism 3130x1 Genetic Analyzer (Applied Biosystems) in accordance with the manufacturer's instructions. The presence or absence of gene mutations at each site was determined by reading using a sequence scanner (Applied Biosystems).

\section{Minimum inhibitory concentrations}

The minimum inhibitory concentrations (MICs) of three agents for $M$. pneumoniae isolates were determined using microdilution methods with PPLO broth, as reported previously $[12,15]$. These agents were erythromycin, minocycline, and levofloxacin. M. pneumoniae strain M129 was used as a control. Serial twofold dilutions of antibiotics prepared in PPLO broth containing $10^{4}$ to $10^{5} \mathrm{CFU} / \mathrm{mL}$ of $M$. pneumoniae were placed in 96-well microplates [12,15]. The microplates were sealed with adhesive sheets and incubated at $37^{\circ} \mathrm{C}$. The MIC was determined as the lowest concentration of antimicrobial agent at which the color of the control medium changed.

\section{Statistical analysis}

Statistical analysis was performed using Stat View version 5.0. (SAS Institute Inc, Cary, NC, USA). The incidence of clinical findings was analyzed using Fisher's Exact test, and laboratory data were compared using Student's $t$ test.

\section{Results}

Prevalence of macrolide-resistant M. pneumoniae in different age groups

During the study period, 1060 CAP cases were enrolled in this study. A total of 423 cases were pediatric patients less than 16 years old, 124 cases were 16 to 19 -year-old adolescent patients, and 513 cases were adult patients. A microbiological diagnosis was established in $56 \%$ of pediatric patients, $59 \%$ of adolescent patients, and $54 \%$ of adult patients. The most common pathogens were $M$. pneumoniae (23\%) followed by Haemophilus influenzae (15\%) and S. pneumoniae (8\%) in pediatric patients, $M$. pneumoniae (29\%) followed by S. pneumoniae (14\%) and $H$. influenzae (10\%) in adolescent patients, and $S$. pneumoniae (26\%) followed by M. pneumoniae (10\%) and $H$. influenzae (7\%) in adult patients.

Of all CAP cases, 99 cases were positive for $M$. pneumoniae in culture and/or by the PCR method. Of these, all cases were PCR positive, 40 cases were culture positive and 85 cases demonstrated positive serological results. No other microorganisms were detected in these cases. Forty-five cases were pediatric patients, 26 cases were adolescent patients and 28 cases were adult patients.

Thirty of 45 pediatric patients (66\%), 12 of 26 adolescent patients $(46 \%)$, and seven of 28 adult patients (25\%) with M. pneumoniae pneumonia were found to be infected with macrolide-resistant $M$. pneumoniae (MR) patients. The prevalence of macrolide-resistant M. pneumoniae in different age groups from 2008 to 2011 is presented in Figure 1. Among adolescent patients, macrolide-resistant $M$. pneumoniae was identified in two of six patients in 2008, two of six patients in 2009, two of four patients in 2010 and six of 10 patients in 2011 .

\section{Patient characteristics}

Table 1 shows the characteristics of MR and macrolidesensitive M. pneumoniae (MS) patients in different age groups. As reported by Lucier et al. [20], Okazaki et al. [13], and Morozumi et al. [14], an A-to-G transition or A-to-C transversion at positions 2063 or 2064 in domain $\mathrm{V}$ on the $23 \mathrm{~S}$ rRNA gene results in resistance to macrolide antibiotics. Among 30 pediatric MR patients, 26 had an A-to-G transition at position 2063 (A2063G) and four had an A-toG transition at position 2064 (A2064G). In 12 adolescent MR patients, 10 showed an A2063G transition and two showed an A2064G transition, and in seven adult MR patients, six showed an A2063G transition and one showed 


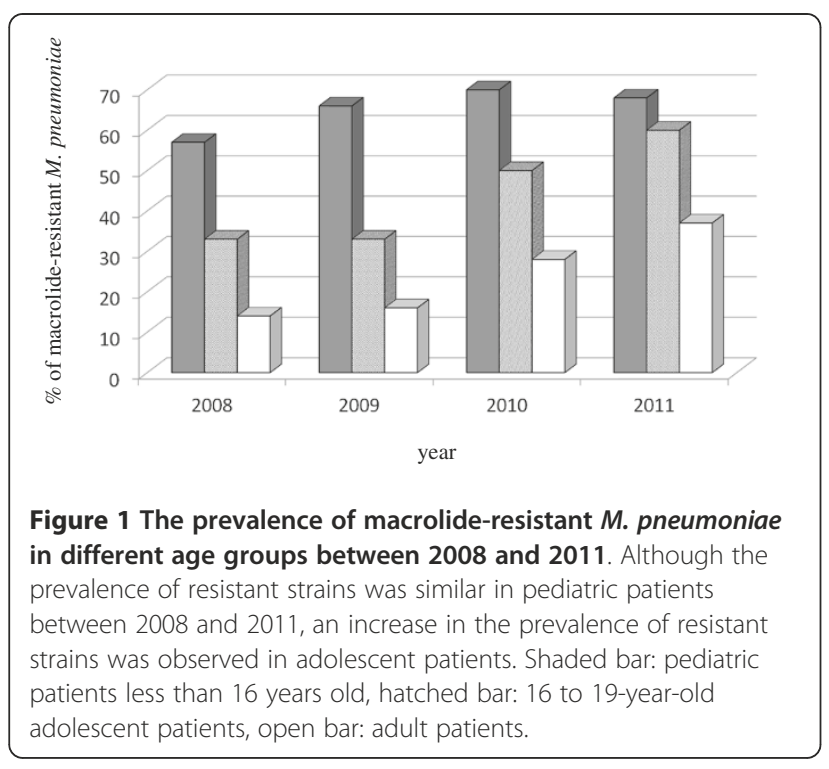

an A2064G transition. No mutations at site 2617 in domain $\mathrm{V}$ of the $23 \mathrm{~S}$ rRNA gene were observed. In terms of clinical symptoms and laboratory findings, no significant differences were observed between MR patients and MS patients in different age groups.

\section{Minimum inhibitory concentrations}

Twenty-two isolates of $M$. pneumoniae with a mutation of the $23 \mathrm{~S}$ rRNA gene showed resistance to erythromycin with a MIC of 128 to $>128 \mathrm{mg} / \mathrm{L}\left(\mathrm{MIC}_{90}\right.$ of $>128 \mathrm{mg} / \mathrm{L}$ ), whereas the other 18 isolates without a mutation of the $23 \mathrm{~S}$ rRNA gene showed susceptibility to erythromycin with a MIC of 0.00195 to $0.0078 \mathrm{mg} / \mathrm{L}\left(\mathrm{MIC}_{90}\right.$ of $\left.0.0078 \mathrm{mg} / \mathrm{L}\right)$. The MICs for minocycline and levofloxacin for macrolideresistant isolates were equal to the MIC for susceptible isolates at 0.25 to $2 \mathrm{mg} / \mathrm{L}\left(\mathrm{MIC}_{90}\right.$ of $\left.1 \mathrm{mg} / \mathrm{L}\right)$ and 0.25 to $1 \mathrm{mg} / \mathrm{L}\left(\mathrm{MIC}_{90}\right.$ of $\left.0.5 \mathrm{mg} / \mathrm{L}\right)$, respectively.

\section{Discussion}

Macrolides are generally considered to be the first-choice agents for the treatment of M. pneumoniae infection. Tetracyclines and fluoroquinolones are effective in the treatment of $M$. pneumoniae infection, but the administration of these agents to children is not recommended because of their toxicity. Tetracyclines have the potential to repress bone growth, cause permanent gray-brown discoloration of the teeth, and enamel hypoplasia when given during tooth development. The clinical importance of fluoroquinolones has not been demonstrated because they have been known to cause cartilage erosion in

Table 1 Characteristics of patients with macrolide-resistant (MR) and macrolide-sensitive (MS) Mycoplasma pneumoniae pneumonia in different age groups

\begin{tabular}{|c|c|c|c|c|c|c|}
\hline \multirow[t]{2}{*}{ Characteristic } & \multicolumn{2}{|c|}{ Pediatric patients } & \multicolumn{2}{|c|}{ Adolescent patients } & \multicolumn{2}{|c|}{ Adult patients } \\
\hline & MR & MS & MR & MS & MR & MS \\
\hline Number & 30 & 15 & 12 & 14 & 7 & 21 \\
\hline Age range, years & $1-15$ & $1-15$ & $16-19$ & $16-19$ & $20-42$ & $28-45$ \\
\hline Male:female & $16: 14$ & $7: 8$ & $6: 6$ & $8: 6$ & $4: 3$ & $11: 10$ \\
\hline \multicolumn{7}{|l|}{ 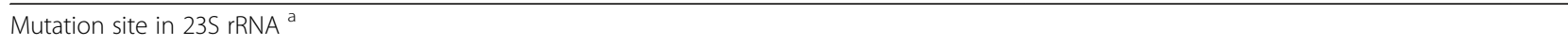 } \\
\hline A2063G & 26 & & 10 & & 6 & \\
\hline A2064G & 4 & & 2 & & 1 & \\
\hline No. of patients prescribed macrolides (\%) & $23(76)$ & $15(100)$ & $9(75)$ & $9(64)$ & $5(71)$ & $6(28)$ \\
\hline Clarithromycin & 12 & 10 & 5 & 4 & 2 & 2 \\
\hline Azithromycin & 11 & 5 & 4 & 5 & 3 & 4 \\
\hline $\begin{array}{l}\text { No. of patients with a change of prescription after macrolide } \\
\text { administration (\%) }\end{array}$ & $20(66)$ & 0 & $7(58)$ & $3(21)$ & $3(42)$ & $4(19)$ \\
\hline Minocycline & 16 & & 5 & 3 & 1 & 1 \\
\hline Quinolones & $4^{b}$ & & 2 & 0 & 2 & 3 \\
\hline \multicolumn{7}{|l|}{ Clinical symptoms and laboratory findings at the first examination } \\
\hline Cough & 30 & 15 & 12 & 14 & 7 & 21 \\
\hline Sputum & 23 & 11 & 7 & 8 & 4 & 12 \\
\hline Fever, temperature $\geq 38^{\circ} \mathrm{C}$ & 26 & 14 & 11 & 13 & 7 & 21 \\
\hline Respiratory rate, $>30 / \mathrm{min}$ & 2 & 1 & 0 & 0 & 0 & 0 \\
\hline White Blood Cell, mean (/uL) & 6,410 & 6,520 & 6,810 & 7,010 & 6,620 & 6,710 \\
\hline C-reactive protein, mean (mg/dL) & 2.1 & 1.9 & 3.1 & 3.3 & 3.7 & 3.5 \\
\hline
\end{tabular}

${ }^{a}$ A2063G: A-to-G transition at position 2063 in domain $V$ on the $23 S$ rRNA gene.

A2064G: A-to-G transition at position 2064.

${ }^{\mathrm{b}}$ Tosufloxacin used. 
young animals. Thus, these agents should be avoided when alternatives can be used. In contrast to pediatric patients, fluoroquinolones and tetracyclines are usually administered to adult patients with respiratory tract infections. These agents demonstrate good clinical efficacy against macrolideresistant $M$. pneumoniae infection. Adolescent patients usually visit a general physician not a pediatrician and fluoroquinolones and tetracyclines may often be administered against respiratory tract infections. General physicians may readily treat respiratory infections using these agents in adult and adolescent patients. Thus, the investigation of macrolide-resistant $M$. pneumoniae infections has been carried out only among the pediatricians in Japan.

In a previous study, we first reported macrolide-resistant M. pneumoniae infections in adults ( $\geq 20$ years old) in Japan [15]. In the present study, the prevalence of macrolideresistant $M$. pneumoniae was similar between pediatric and adolescent patients especially in 2011. Point mutations in domain V of $23 \mathrm{~S}$ rRNA were also identical between these two groups. Physicians should pay attention to macrolideresistant $M$. pneumoniae not only in children but also in adolescent patients, especially those of high-school age.

In 2009, the first adult case of CAP caused by macrolideresistant $M$. pneumoniae was described in Japan [21]. We have been investigating the prevalence of macrolideresistant $M$. pneumoniae in both children and adults since 2005 , and we identified among adult patients, one of seven patients in 2008, one of six patients in 2009, two of seven patients in 2010, and three of eight patients in 2011 were infected with macrolide-resistant $M$. pneumoniae [15]. Thus, the prevalence of macrolide-resistant $M$. pneumoniae may be increasing in adult patients.

Macrolide-resistant $M$. pneumoniae is also emerging in other several countries especially in children [5,22-26]. A recent study in China has shown macrolide resistance in $69 \%$ of $M$. pneumoniae isolates from adolescent and adult patients [26]. Thus, monitoring of $M$. pneumoniae strains seems to be necessary in order to recognize early changes in the antibiotic resistance pattern of this important agent of human respiratory tract infections.

Our study had limitations; we evaluated PCR-positive patients (of these, 40 cases were culture positive). As reported by several researchers, an A2063G transition and an A2064G transition in domain $\mathrm{V}$ of the $23 \mathrm{~S}$ rRNA gene resulted in resistance to macrolide antibiotics [13-15,20]. Among the 49 MR patients studied, 32 had A2063G and seven had A2064G. Most of these isolates were highly resistant to 14- and 15-membered ring macrolides with MICs greater than or equal to $32 \mu \mathrm{g} / \mathrm{mL}$ [13-15,20]. Thus, these data indicate that our PCR-positive patients with point mutations at positions 2063 or 2064 in domain $\mathrm{V}$ on the $23 \mathrm{~S}$ rRNA gene were resistant to macrolides. Furthermore, the number of patients characterized as adolescents was very low to clarify the prevalence of resistance in this age group. A large-scale surveillance study to investigate the frequency of macrolide-resistant $M$. pneumoniae cases is needed.

\section{Conclusions}

The prevalence of macrolide-resistant M. pneumoniae is high among adolescent patients as well as pediatric patients less than 16-years old. To prevent outbreaks of $M$. pneumoniae infection, especially macrolide-resistant $M$. pneumoniae, in closed populations including among families, in schools, and in university students, physicians should pay careful attention to the potential occurrence of infections involving macrolide-resistant M. pneumoniae.

\section{Competing interests}

The authors declare that they have no competing interests.

\section{Authors' contributions}

$\mathrm{NM}, \mathrm{KO}$ and $\mathrm{NO}$ conceived the study and participated in its design and coordination. NM, YK, HA, TH, TK and the Atypical Pathogen Study Group members collected and managed the data, including quality control, and carried out the microbiological laboratory tests. NM, KO and NO drafted the manuscript, and all authors contributed substantially to its revision. All the authors read and approved the final manuscript.

\section{Acknowledgments}

We thank the members of the Atypical Pathogen Study Group: Takaya Maruyama (Mie University Graduate School of Medicine), Chikara Nakahama (Nakahama Clinic), Hirohide Yoneyama (Kasaoka Daiichi Hospital), Niro Okimoto (Kawasaki Hospital), Masayasu Kawanishi (Kaneda Hospital), Makoto Kimura (Kimura Clinic), Toshiharu Matsushima (Kurashiki Daiichi Hospital), Masao Kuwabara (Kenritsu Hiroshima Hospital), Kouji Hashiguchi (Nagasaki Genbaku Hospital), and Yasuhiro Nagatomo (University of Miyazaki). This work was supported by MEXT KAKENHI (19591190 and 21591304) and Project Research Grants from Kawasaki Medical School (13-401, 14-402, 15-405A, 16-405 M, 17-402 M, 18-401, 19-402 M, 20-4030).

\section{Author details}

${ }^{1}$ Department of Internal Medicine I, Kawasaki Medical School, 2-1-80 Nakasange, Kita-ku, Okayama 700-8505, Japan. ${ }^{2}$ Department of Pediatrics, Kawasaki Medical School, 577 Matsushima, Kurashiki 701-0192, Japan.

Received: 19 December 2011 Accepted: 31 May 2012

Published: 31 May 2012

\section{References}

1. The committee for the Japanese Respiratory Society guidelines in management of respiratory infections: The Japanese Respiratory Society guideline for the management of community-acquired pneumonia in adults. Respirology 2006, 11(Suppl 3):79-133.

2. National Institute of Health: Infectious Disease Surveillance Center. Mycoplasma pneumoniae pneumonia. 2000. http://idsc.nih.go.jp/idwr/kanja/ weeklygraph/18myco.html.

3. Rasmussen JN, Voldstedlund M, Andersen RL, Ellermann-Eriksen S, Jensen TG, Johansen HK, Kolmos B, Molvadgaard M, Nielsen SS, Olsen E, Schonning K, Uldum SA: Increased incidence of Mycoplasma pneumoniae infections detected by laboratory-based surveillance in Denmark in 2010. Euro Surveill 2010, 15:45.

4. Chalker V, Stocki T, Mentasti M, Fleming D, Harrison T: Increased incidence of Mycoplasma pneumoniae infection in England and Wales in 2010: multiocus variable number tandem repeat analysis typing and macrolide susceptibility. Euro Surveill 2011, 16:19.

5. Averbuch D, Hidalgo-Grass C, Moses AE, Engelhard D, Nir-Paz R: Macrolide resistance in Mycoplasma pneumoniae, Israel, 2010. Emerg Infect Dis 2011, 17(6):1079-1082. 
6. Polkowska A, Harjunpää A, Toikkanen S, Lappalainen M, Vuento R, Vuorinen T, Kauppinen J, Flinck H, Lyytikäinen O: Increased incidence of Mycoplasma pneumoniae infection in Finland, 2010-2011. Euro Surveill 2012, 17(5).

7. Blystad H, Anestad G, Vestrheim DF, Madsen S, Ronning K: Increased incidence of Mycoplasma pneumoniae infection in Norway 2011. Euro Surveill 2012, 17(5)

8. Uldum SA, Bangsborg JM, Gahrn-Hansen B, Ljung R, Molvadgaard M, Fons Petersen R, Wiid Svarrer C: Epidemic of Mycoplasma pneumoniae infection in Denmark, 2010 and 2011. Euro Surveill 2012, 17(5).

9. Chalker VJ, Stocki T, Litt D, Bermingham A, Watson J, Fleming DM, Harrison TG: Increased detection of Mycoplasma pneumoniae infection in children in England and Wales, October 2011 to January 2012. Euro Surveill 2012, $17: 6$.

10. Linde A, Ternhag A, Törner A, Claesson BE: Antibiotic prescriptions and laboratory-confirmed cases of Mycoplasma pneumoniae during the epidemic in Sweden in 2011. Euro Surveill 2012, 17:6.

11. Eibach D, Escuret V, Billaud G, Mekki Y, Frobert E, Bouscambert-Duchamp M, Lina B, Morfin F: Increased detection of Mycoplasma pneumoniae infection in children, Lyon, France, 2010 to 2011. Euro Surveill 2012, 17:8.

12. Matsuoka M, Narita M, Okazaki N, Ohya H, Yamazaki T, Ouchi K, Suzuki I, Andoh T, Kenri T, Sasaki Y, Horino A, Shintani M, Arakawa Y, Sasaki T: Characterization and molecular analysis of macrolide-resistant Mycoplasma pneumoniae clinical isolates obtained in Japan. Antimicrob Agents Chemother 2004, 48(12):4624-4630.

13. Okazaki N, Narita M, Yamada S, Izumikawa K, Umetsu M, Kenri T, Sasaki Y, Arakawa Y, Sasaki T: Characteristics of macrolide-resistant Mycoplasma pneumoniae strains isolated from patients and induced with erythromycin in vitro. Microbiol Immunol 2001, 45(8):617-620.

14. Morozumi M, Takahashi T, Ubukata K: Macrolide-resistant Mycoplasma pneumoniae: characteristics of isolates and clinical aspects of community-acquired pneumonia. J Infect Chemother 2010, 16(2):78-86.

15. Miyashita N, Kawai Y, Yamaguchi T, Ouchi K, Oka M, Atypical Pathogen Study Group: Macrolide-resistant Mycoplasma pneumoniae in adults with community-acquired pneumonia. Int J Antimicrob Agents 2010, 36(4): 384-385.

16. Suzuki S, Yamazaki T, Narita M, Okazaki N, Suzuki I, Andoh T, Matsuoka M, Kenri T, Arakawa Y, Sasaki T: Clinical evaluation of macrolide-resistant Mycoplasma pneumoniae. Antimicrob Agents Chemother 2006, 50(2): 709-712.

17. Matsubara K, Morozumi M, Okada T, Matsushima T, Komiyama O, Shoji M, Ebihara T, Ubukata K, Sato Y, Akita H, Sunakawa K, Iwata S: A comparative clinical study of macrolide-sensitive and macrolide-resistant Mycoplasma pneumoniae infections in pediatric patients. $J$ Infect Chemother 2009, 15(6):380-383.

18. Kawai Y, Miyashita N, Yamaguchi T, Saitoh A, Kondoh E, Fujimoto H, Teranishi H, Inoue M, Wakabayashi T, Akaike H, Ogita S, Kawasaki K, Terada K, Kishi F, Ouchi K: Clinical efficacy of macrolide antibiotics against genetically determined macrolide-resistant Mycoplasma pneumoniae pneumonia in pediatric patients. Respirology 2012, 17(2):354-362.

19. Miyashita N, Kawai Y, Yamaguchi T, Ouchi K, Oka M, Atypical Pathogen Study Group: Clinical potential of diagnostic methods for the rapid diagnosis of Mycoplasma pneumoniae pneumonia in adults. Eur J Clin Microbiol Infect Dis 2011, 30(3):439-446.

20. Lucier TS, Heitzman K, Liu SK, Hu PC: Transition mutations in the $23 \mathrm{~S}$ rRNA of erythromycin-resistant isolates of Mycoplasma pneumoniae. Antimicrob Agents Chemother 1995, 39(12):2770-2773.

21. Isozumi R, Yoshimine H, Morozumi M, Ubukata K, Ariyoshi K: Adult community-acquired pneumonia caused by macrolide resistant Mycoplasma pneumoniae. Respirology 2009, 14(8):1206-1208.

22. Peuchant $\mathrm{O}$, Menard A, Renaudin H, Morozumi M, Ubukata K, Bebear CM, Pereyre S: Increased macrolide resistance of Mycoplasma pneumoniae in France directly detected in clinical specimens by real-time PCR and melting curve analysis. J Antimicrob Chemother 2009, 64(1):52-58.

23. Wolff BJ, Thacker WL, Schwartz SB, Winchell JM: Detection of macrolide resistance in Mycoplasma pneumoniae by real-time PCR and highresolution melt analysis. Antimicrob Agents Chemother 2008, 52(10): 3542-3549.

24. Dumke R, von Baum H, Luck PC, Jacobs E: Occurrence of macrolideresistant Mycoplasma pneumoniae strain in Germany. Clin Microbial Infect 2010, 16(6):613-616

25. Chironna M, Sallustio A, Esposito S, Perulli M, Chinellato I, Di Bari C, Quarto $M$, Cardinale F: Emergence of macrolide-resistant strains during an outbreak of Mycoplasma pneumoniae infections in children. J Antimicrob Chemother 2011, 66(4):734-737.

26. Cao B, Zhao CJ, Yin YD, Zhao F, Song SF, Bai L, Zhang JZ, Liu YM, Zhang YY, Wang $\mathrm{H}$, Wang $\mathrm{C}$ : High prevalence of macrolide resistance in Mycoplasma pneumoniae isolates from adult and adolescent patients with respiratory tract infection in China. Clin Infect Dis 2010, 51(2):189-194.

doi:10.1186/1471-2334-12-126

Cite this article as: Miyashita et al:: Macrolide-resistant Mycoplasma pneumoniae in adolescents with community-acquired pneumonia. BMC Infectious Diseases 2012 12:126.

\section{Submit your next manuscript to BioMed Central and take full advantage of:}

- Convenient online submission

- Thorough peer review

- No space constraints or color figure charges

- Immediate publication on acceptance

- Inclusion in PubMed, CAS, Scopus and Google Scholar

- Research which is freely available for redistribution

Submit your manuscript at www.biomedcentral.com/submit
C) Biomed Central 